\title{
Preservation of high pressure mineral assemblages in felsic gneisses: influences of bulk composition and hydration versus dehydration reactions
}

\author{
S. J. CUTHBERT
}

Dept. of Mineralogy, Petrography and
Geochemistry, AGH University of Science
and Technology, 30-059 Krakow, Poland

The felsic rocks of eclogite terrains in orogens usually lack eclogite-facies mineral assemblages and are often dominantly of the amphibolite-facies. Hence they have undergone pervasive retrogression that the mafic eclogites have often escaped, possibly due to contrasting hydration versus dehydration reaction pathways of eclogite and their felsic hosts. Insights into the retrogression behaviour of the predominant felsic rocks have been gained from the Sunnfjord area in the southern Norwegian Caledonides, where charnockitic precursors of mafic to granitoid compositions have been transformed under sub-solidus conditions peaking at $675^{\circ} \mathrm{C}, 2.35 \mathrm{GPa}$. They then underwent variable retrogression, the extent of which correlates with bulk composition. Aqueous fluid was first introduced under epidote-amphibolite conditions during subduction. Petrography, combined with pseudosection analysis, show that Ca-rich, K-poor gneisses favoured low phengite, omphacite-rich parageneses at peak $\mathrm{P}$ (note that they evolved by dehydration of prograde amphibolite). Subsequently, they required ingress of aqueous fluid to retrogress to the lower density amphibolite parageneses; the extent of retrogression was constrained by limited availability of water. More K-rich, Ca-poor gneisses would have had less clinopyroxene and much more phengite at peak P (retaining water acquired during subduction), the latter decomposing spontaneously by dehydration upon decompression, with no constraint from water availability, hence the reaction tended to be more rapid and complete. Omphacite in the K-poor felsic gneisses shows some replacement by symplectite, though this always contains amphibole in addition to diopsidic cpx, hence requiring aqueous fluid as a reactant. Water possibly also acted to initiate symplectite-forming reactions and control reaction rates. These results demonstrate that subtle variations in bulk composition in felsic gneisses can lead to variable reaction completion due to contrasting metamorphic water budgets. It is implied that adjacent rock volumes may evolve or consume water in different ways at different times along their P-T cycle. 